\title{
əDesign and Experimental Study of a Novel Full-Ocean-Depth Pressure-Retaining Sediment Sampler
}

\author{
Shudong He, ${ }^{a}$ Youduo Peng,,${ }^{\mathrm{a}}$ YongPing Jin,,${ }^{\mathrm{a}}$ Jan Yan, ${ }^{\mathrm{a}}$ AND Buyan Wan ${ }^{\mathrm{a}}$

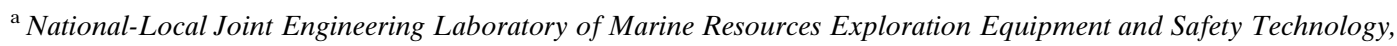 \\ Hunan University of Science and Technology, Xiangtan, China
}

(Manuscript received 27 December 2020, in final form 18 July 2021)

\begin{abstract}
Deep-sea sediments hold evolutionary records of the oceanic environment-records of great significance for scientific fields investigating marine sedimentary processes, structural evolution, and seabed mineral resource exploration. However, the acquisition of original samples from deep-sea sediments is completely dependent on advanced seabed sediment collection methods and technical equipment. In this paper, a novel sampler is proposed to obtain intact sediment samples at full ocean depth. It mainly consists of a sampling device, pressure-retaining device, pressure-compensating device, and sample transfer device. The sampler can collect samples at full ocean depth $(11000 \mathrm{~m})$ with a maximum core diameter of $54 \mathrm{~mm}$ and core length of $350 \mathrm{~mm}$, and samples can be maintained at near-in situ pressures during recovery. The sampler can be installed on a remote-operated vehicle or human-occupied vehicle, and it can be operated with a single mechanical arm to collect pressure-retained samples. The experimental test showed that the novel sampler had good pressure-retaining performance and suitability with a mechanical arm, and can be applied to pressure-retaining sampling of seabed sediments at depth of $11000 \mathrm{~m}$.
\end{abstract}

KEYWORDS: Atmosphere; Ocean; Numerical analysis; Pressure

\section{Introduction}

The ocean is the cradle of life on Earth, with at least $50 \%$ of the total biosphere lying below a depth of $1000 \mathrm{~m}$ (Wang et al. 2020). As compared with continental ecological environments, our understanding of deep-sea ecosystems is still very limited because of the difficulty in accessing deep water layers (Drazen and Yeh 2012). Such an environment is characterized as being particularly harsh, with a lack of light, low temperatures, high pressure, etc. However, pressure-sensitive microorganisms and aerobic microorganisms are well suited to this extreme environment (Nunoura et al. 2015; Ritchie et al. 2017). The study of microorganisms in this extreme environment can improve our understanding of the deep-sea survival principles governing microorganisms and provide insight into the evolution of life on Earth (Huang et al. 2006). At present, full understanding of the ecology and biology of deep-sea biological communities is obstructed by the difficulty in obtaining the original intact samples (Shillito et al. 2015). Maintaining the pressure of the deep sea during transport to the surface is the biggest challenge. Loss of pressure in the sediment will lead to a dissolution of gas phase, decomposition of organic matter, death of barophilic microorganism, etc. (Huang et al. 2018). Because of the technical limitations of pressure-retaining sampling, only an estimated $0.01 \%$ of the total ocean area has been sampled and studied (Ramirez-Llodra et al. 2010). Therefore, it is of great importance to research and develop a sampler capable of obtaining high fidelity samples.

¿ Denotes content that is immediately available upon publication as open access.

Corresponding author: Youduo Peng, ydpeng1964@163.com
To date, a series of sediment pressure-retaining samplers have been made. For example, the pressure core barrel (Peterson 1984) developed in the Deep Sea Drilling Project was successfully deployed on the Blake Outer Ridge to a water depth of $3184 \mathrm{~m}$, and the system worked with a pressure up to $34.4 \mathrm{MPa}$, while sediments had an in situ pressure ranging from 10.3 to 32.3 MPa. The pressure core sampler (PCS; Pettigrew 1992) developed by the Ocean Drilling Project was a free-fall, hydraulically actuated wire-line tool designed to retrieve a core at near-in situ pressure. The working pressure is up to $69 \mathrm{MPa}$. The PCS was deployed at a depth of $6500 \mathrm{~m}$, and the recovery rate was $60.8 \%$. The pressure temperature core system (PTCS) (Masayuki et al. 2006) developed by Japan was designed to control the temperature and pressure of the core with a maximum working pressure of $24 \mathrm{MPa}$. The PTCS was deployed at a maximum water depth of $1006 \mathrm{~m}$, and the recovery rate was 79.3\%. The Hybrid PCS (Kubo et al. 2014) developed by Japan Marine Science and Technology Center was mainly the combined design of PTCS and PCS. The working pressure of the Hybrid PCS was $35 \mathrm{MPa}$. The Hybrid PCS was deployed at a depth of $1000 \mathrm{~m}$, and the recovery rate was $69 \%$. The multiple autoclave corer (Abegg et al. 2008) proposed by Abegg et al. was equipped with four coring cylinders and an underwater television system, with working pressure of $20 \mathrm{MPa}$ and a working water depth less than $2200 \mathrm{~m}$. The high-pressure temperature coring system (HPTC; Schultheiss et al. 2009) was designed by the Gulf of Mexico Joint Industry Project. The HPTC had a rotary coring system, and the maximum working pressure of the HPTC was $35 \mathrm{MPa}$. Detailed descriptions (i.e., sampling technique, sealing technique, pressure-retaining technique, and temperature-retaining technique) of the samplers mentioned above have been provided in documents (He et al. 2020), and they can maintain in situ pressure through good recovery techniques, but can only be deployed on a large 


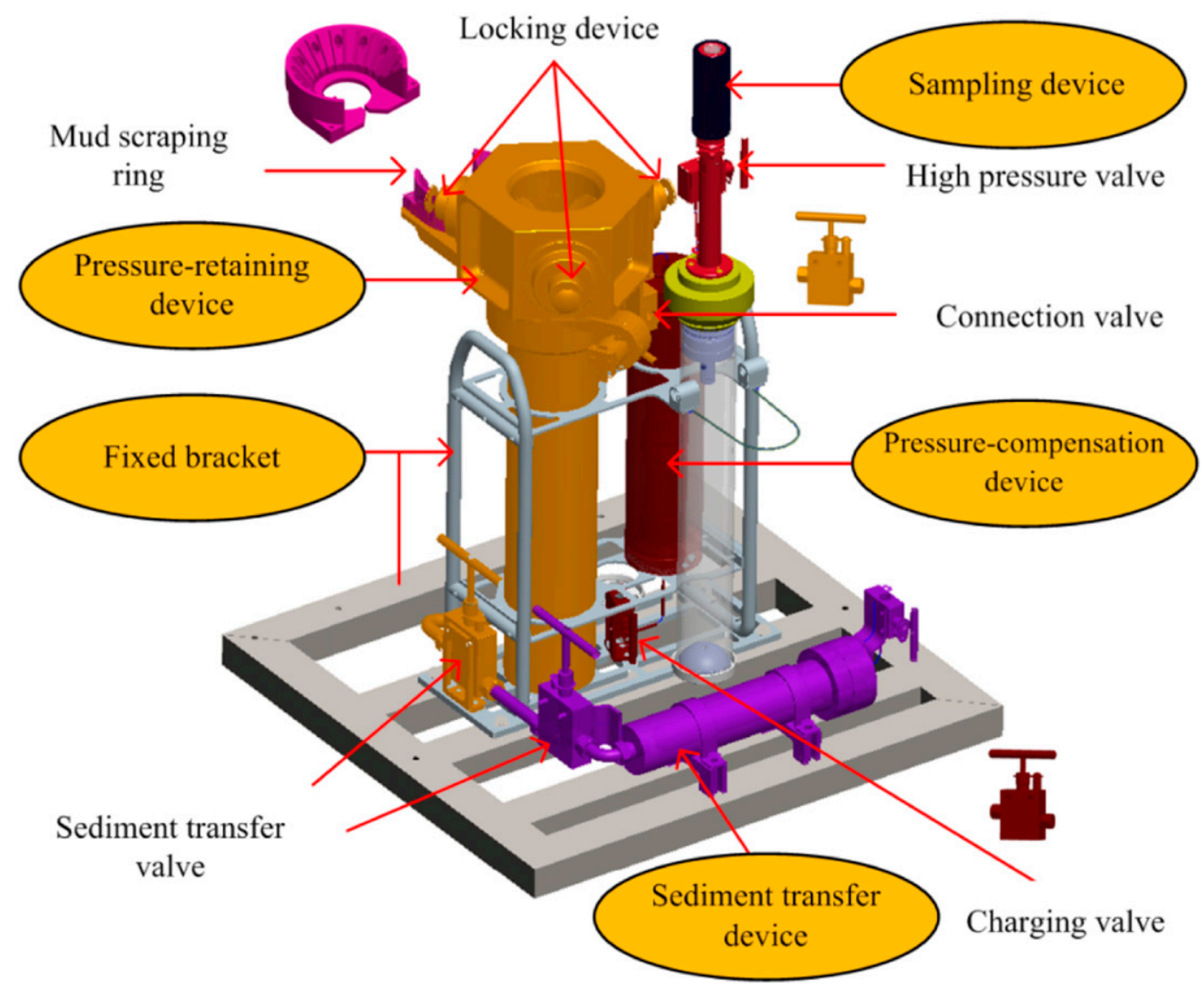

FIG. 1. Three-dimensional model of the sampler.

drilling vessel such as Chikyu (Kubo et al. 2014) at water depths of less than $7000 \mathrm{~m}$.

To reach deeper sea areas for sampling, samplers mounted on remote-operated vehicle (ROV) or human-occupied vehicle (HOV) for sampling have gained an increasing amount of attention. The U.S. ROV "Jasson" and the French ROV "Victor 6000" have been equipped with sediment sampling devices (Mittelstaedt et al. 2012), which could collect samples from the seabed sediment (about a depth $7000 \mathrm{~m}$ ) and maintain in situ pressure during sample retrieval and shipment back to onshore laboratories. People et al. proposed an onboard pressure-retaining sampler and conducted a sea test to a depth of $10970 \mathrm{~m}$. The sample pressure was maintained at about $90 \mathrm{MPa}$ (People et al. 2019), but the pressure-retaining rate still needed to be improved. China's HOV "Jiaolong" ( $\mathrm{Lu}$ et al. 2019) was equipped with a pressure-retaining sampler, which was able to retain the in situ pressure of sediment samples from $7000 \mathrm{~m}$. However, the entire sampling process could only be completed with the coordination of the ROV's two mechanical arms, which made the sampling process technically challenging. To address the technical considerations of working in deep-sea environments, Case et al. designed a new high-volume, high-pressure (HP)-sediment core sampler that was deployable on the payload of an ROV and can maintain in situ HP conditions. A unique function of the HP-core system was the ability to supply liquid and gas substrates while maintaining the constant pressure in the chamber (Case et al. 2018). However, the maximum working water depth is about $5000 \mathrm{~m}$.

Scientific research institutions and scholars focus on the study of pressure-retaining samplers designed for water depths less than $7000 \mathrm{~m}$. There are very few sediment samplers rated for water depths of more than $7000 \mathrm{~m}$, capable of obtaining samples with information of mineral resources, biological resources, and microbial communities intact. This is because maintaining pressure in sediment samples from an ultradeep seabed environment requires incredibly robust and technically complicated equipment. To address this technical challenge, a novel sediment sampler for obtaining pressure-retained samples at full ocean depth $(11000 \mathrm{~m})$ is proposed in this paper. It is compact in structure, light in weight, easy to operate, and good in pressure-retaining performance.

\section{Structure and working principle}

The structure of the novel sampler is shown in Fig. 1. It consists primarily of a sampling device, a pressure-retaining device, a pressure-compensation device, a sample transfer device, a fixed bracket, high-pressure pipelines, and high-pressure valves. The working principle and process are as follows. 
The sampler was designed to be carried on an HOV. When the HOV reaches the sampling point, a single mechanical arm can be used to collect sediment. Upon collection, the sampling device with collected sediment will be fixed to the pressureretaining cylinder to be sealed and maintained at a constant pressure during recovery to the inspection ship. The specific process is as follows: First, the pressure-retaining sampler proposed is fixed in the tool basket of an HOV. Then the pressure-compensation device is charged with nitrogen with a certain pressure and energy is stored. During diving process, the sampler descends with the HOV. As the depth deepens, the pressure in the pressure-retaining device that connects with the external seawater increases continuously, the pressurecompensation device continues to store energy. Next, when the HOV reaches the sampling point, the mechanical arm grabs the handle of the sampling device from the tool basket and moves the sampling device to the surface of the seabed sediment where it is inserted into the sediment at a certain velocity to collect the sample; then, after collection and cleaning, the sampling device is fixed to the pressure-retaining cylinder. Last, as the sampler ascends with the HOV, the pressure-compensation device will release the pressure into the pressure-retaining cylinder to retain the pressure of the sample in real time.

\section{Design of the pressure-retaining sampler}

According to the deep-sea sampling environment and the requirements of the project, the performance indices for the full-ocean-depth pressure-retaining sampler were established, as shown in Table 1.

\section{a. Pressure-bearing system}

First, the required wall thickness of the pressure-bearing cylinder is determined. Then, based on the thickness, the system pressure loss is calculated to provide a theoretical basis for setting the precharged pressure of the pressurecompensation device.

The novel sampler was made of TC4 titanium alloy with a maximum working pressure of $115 \mathrm{MPa}$, making it an ultrahigh-pressure vessel. The design of pressureretaining cylinder should therefore meet the design criteria of ultrahigh-pressure vessels. According to the Faupel's bursting failure criterion, the formula to calculate the wall thickness requirement for the pressure-retaining cylinder is as follows (Wang and Mark 2020):

$$
\delta_{b}=\frac{D_{i}}{2}\left\{\exp \left[\frac{\sqrt{3} n_{b} P}{2 \sigma_{s}\left(2-\sigma_{s} / \sigma_{b}\right)}-1\right]\right\},
$$

where $\delta_{b}$ is the wall thickness; $D_{i}$ is the inner diameter; $\sigma_{b}$ is the tensile strength at the designated temperature; $\sigma_{s}$ is the yield strength at designated temperature; $n_{b}$ is the design safety factor, where $n_{b}=n_{0} \times n_{1}$, with $n_{0}$ being the safety factor considering the change in load conditions, inspection techniques, quality management, and so on $\left(n_{0} \geq 1.65\right)$ and $n_{1}$ being the reliability factor $\left(n_{1} \geq 1.80\right)$; and $P$ is the designated pressure according to the Faupel's bursting pressure formula (Wang and Mark 2020):
TABLE 1. Performance indices of the novel sampler.

\begin{tabular}{lc}
\hline \hline \multicolumn{1}{c}{ Index } & Requirements \\
\hline Max working depth & Full ocean depth $(11000 \mathrm{~m})$ \\
Core length & $\geq 350 \mathrm{~mm}$ \\
Core diameter & $54 \mathrm{~mm}$ \\
Pressure-retaining rate & $\geq 80 \%$ \\
Weight of the sampler & $\leq 50 \mathrm{~kg}$ \\
\hline
\end{tabular}

$$
P=\frac{2}{\sqrt{3} n_{b}} \sigma_{s}\left(2-\frac{\sigma_{s}}{\sigma_{b}}\right) \ln K
$$

where $K$ is the ratio of outer diameter $D_{o}$ to inner diameter $D_{i}$ of the pressure-retaining cylinder; that is, $K=D_{o} / D_{i}$.

When the sampling is completed, the sampler is sealed. After ascending from the seabed to the sea surface, the pressureretaining cylinder of the sampler will change in volume due to the influence of internal and external pressure differences and temperature changes, which will cause the pressure of the sample in the pressure-retaining cylinder to change. The volume change of the pressure-retaining cylinder caused by pressure change can be calculated.

According to the pressure vessel deformation formula (Cheng 2007), The pressure at the sampling depth is $P_{s}$ and the radial deformation $\Delta D$ and axial deformation $\Delta L$ of the pressure-retaining cylinder under the action of pressure $P_{s}$ are

$$
\begin{aligned}
\Delta D & =\frac{P_{s} D_{i}}{E\left(D_{o}^{2}-D_{i}^{2}\right)}\left[(1-2 \mu) \times D_{i}^{2}+(1+\mu) \times D_{o}^{2}\right] \quad \text { and } \\
\Delta L & =\frac{P_{s} L D_{i}^{2}(1-2 \mu)}{E\left(D_{o}^{2}-D_{i}^{2}\right)}
\end{aligned}
$$

where $D_{i}$ is the inner diameter, $D_{o}$ is the outer diameter, $L$ is the height, and $E_{1}$ is the elastic modulus of TC4 titanium alloy. Therefore, the volume change $\Delta V_{1}$ of the pressure-retaining cylinder under the action of $P_{s}$ is

TABLE 2. Design and calculation parameters of the pressurebearing system.

\begin{tabular}{lc}
\hline \multicolumn{1}{c}{ Parameters } & Values \\
\hline Design pressure $P(\mathrm{~Pa})$ & $1.15 \times 10^{8}$ \\
TC4 elastic modulus $E_{1}(\mathrm{~Pa})$ & $1.13 \times 10^{11}$ \\
Poisson's ratio $\mu$ & 0.34 \\
Material expansion coefficient $\alpha\left({ }^{\circ} \mathrm{C}\right)$ & $7.89 \times 10^{-6}$ \\
Tensile strength of material $\sigma_{b}(\mathrm{~Pa})$ & $9.8 \times 10^{8}$ \\
Yield strength of material $\sigma_{s}(\mathrm{~Pa})$ & $8 \times 10^{8}$ \\
Height of pressure-retaining cylinder $L(\mathrm{~mm})$ & 500 \\
Inner diameter of pressure-retaining cylinder & 63 \\
$\quad D_{i}(\mathrm{~mm})$ & 300 \\
Height of pressure-compensation cylinder & \\
$\quad L_{c}(\mathrm{~mm})$ & 50 \\
Inner diameter of pressure-compensation & \\
$\quad$ cylinder $d_{i}($ mm $)$ & $2.4 \times 10^{9}$ \\
Elastic modulus of seawater $E_{2}(\mathrm{~Pa})$ & $0-30$ \\
Temperature difference $\Delta T\left({ }^{\circ} \mathrm{C}\right)$ & \\
\hline
\end{tabular}




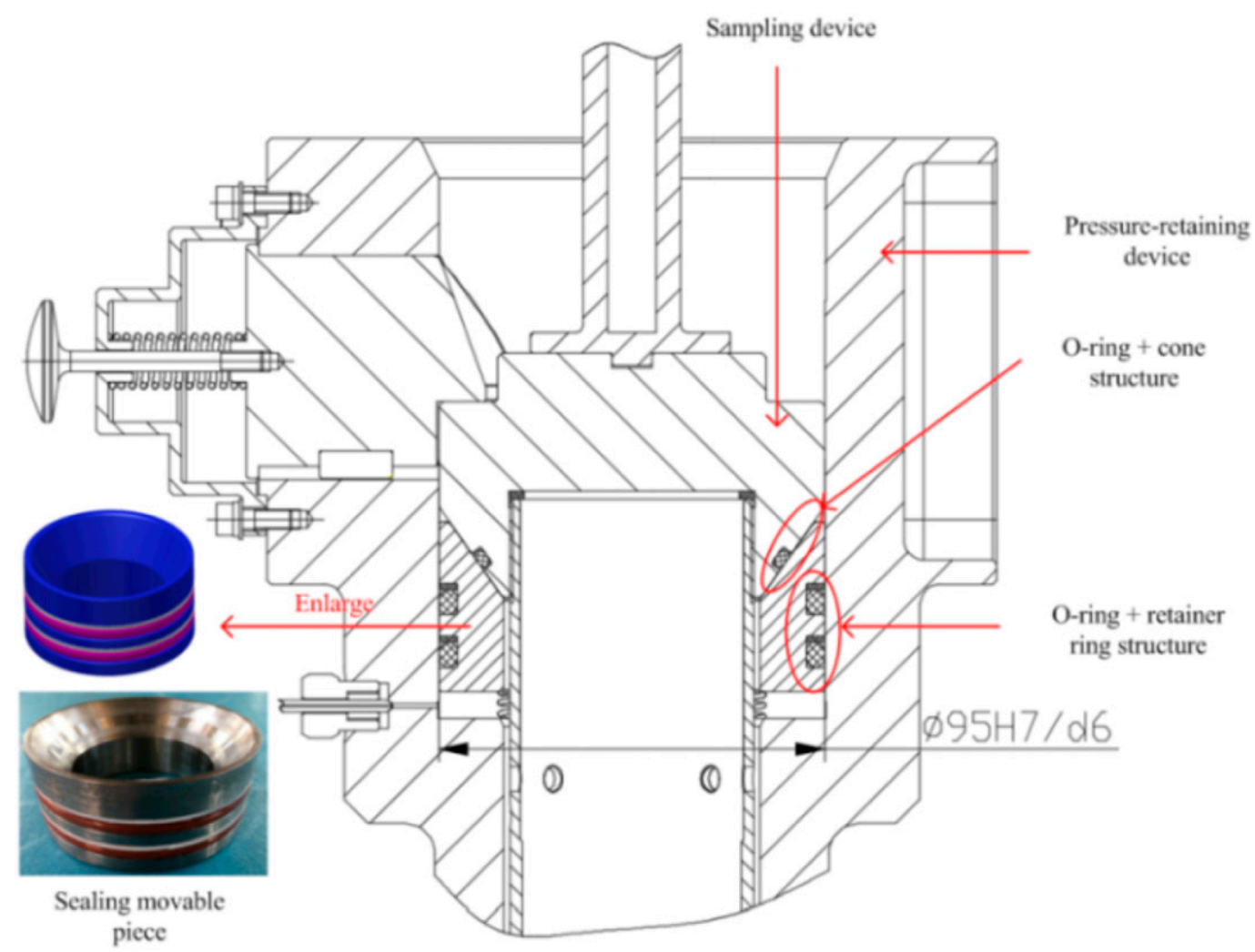

FIG. 2. Combined seal structure.

$$
\Delta V_{1}=\frac{1}{4} \pi\left(D_{i}+\Delta D\right)^{2}(L+\Delta L)-\frac{1}{4} \pi D_{i} L
$$

Then the pressure drop $\Delta P_{1}$ in the pressure-retaining cylinder caused by the expansion of the pressure-retaining cylinder is

$$
\Delta P_{1}=E_{2} \frac{\Delta V_{1}}{V_{0}},
$$

where $E_{2}$ is the elastic modulus of seawater and $V_{0}$ is the original volume of the pressure-retaining cylinder:

$$
V_{0}=\frac{1}{4} \pi D_{i}^{2} L
$$

Then the volume change of the pressure-retaining cylinder caused by temperature difference is calculated. Assuming that the temperature at the sampling point is $T_{s}$ and the sea surface temperature is $T_{0}$, under the temperature difference of $\Delta T=\left|T_{0}-T_{1}\right|$, the internal circumference change $\Delta l_{1}$ and axial deformation $\Delta L_{1}$ of the pressure-retaining cylinder are, according to the pipeline deformation formula ( $\mathrm{Li}$ et al. 2019),

$$
\begin{aligned}
\Delta l_{1} & =\alpha\left(\pi D_{i} \Delta T\right) \quad \text { and } \\
\Delta L_{1} & =\alpha(L \Delta T),
\end{aligned}
$$

where $\alpha$ is the material expansion coefficient. Then, the volume change $\Delta V_{2}$ caused by the temperature difference is

$$
\Delta V_{2}=\frac{\left(\pi D_{i}+\Delta l_{1}\right)^{2}}{4 \pi}\left(L+\Delta L_{1}\right)-\frac{\pi}{4} D_{i}^{2} L .
$$

Thus, the pressure drop $\Delta P_{2}$ caused by temperature difference is obtained as

$$
\Delta P_{2}=E_{2} \frac{\Delta V_{2}}{V_{0}}
$$

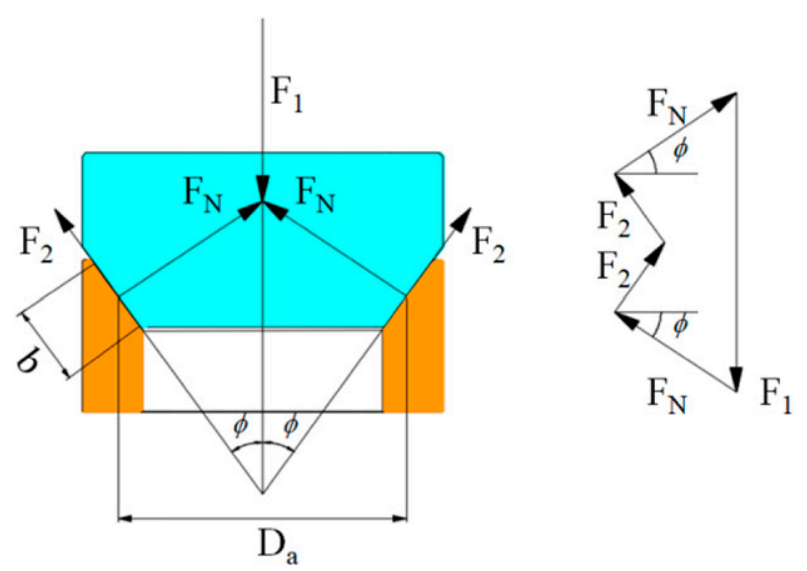

FIG. 3. Force analysis diagram of conical surface seal. 


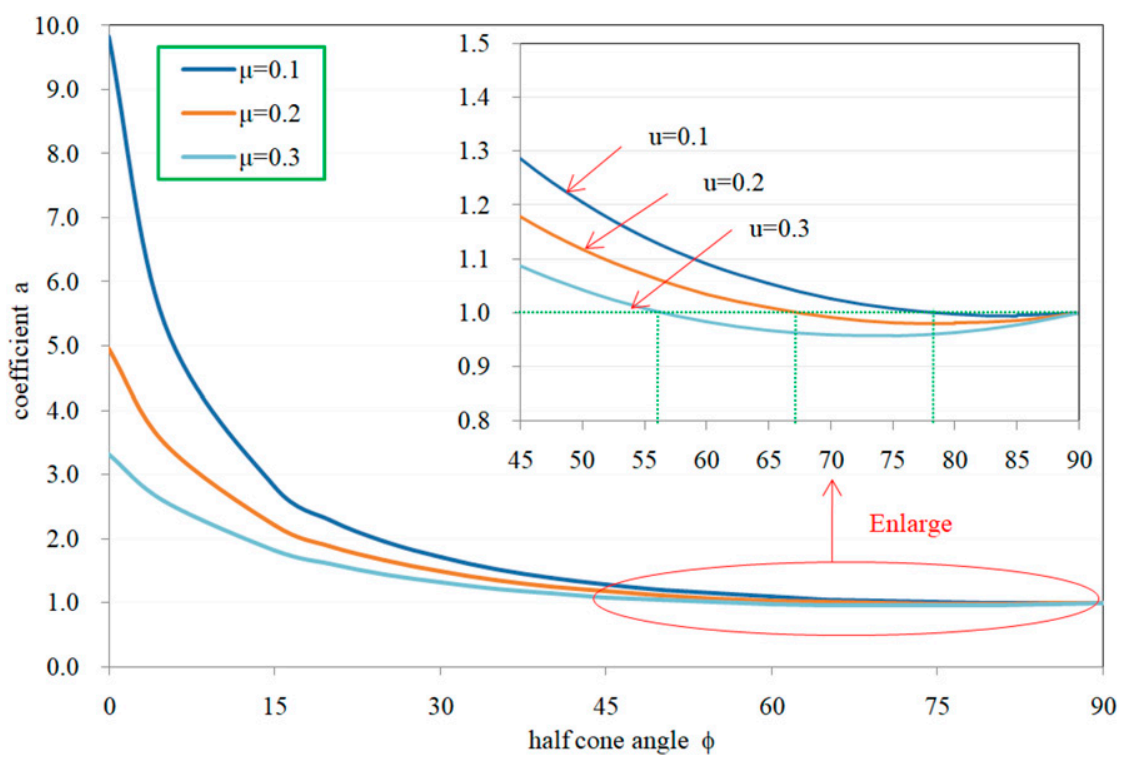

FIG. 4. Relationship between coefficient $a$ and half-cone angle for different friction coefficients.

Then the pressure drop $\Delta P_{b}$ of the pressure-retaining cylinder under the combined action of pressure difference and temperature difference is obtained as

$$
\Delta P_{b}=\Delta P_{1}+\Delta P_{2}
$$

The calculation parameters are shown in Table 2 .

From Eqs. (1)-(12), the following can be obtained: If the wall thickness of the pressure-retaining cylinder is $\delta_{b}=16 \mathrm{~mm}$, its outer diameter is $D_{o}=97 \mathrm{~mm}$. Under the temperature difference of $\Delta T=30^{\circ} \mathrm{C}$, the pressure drop in the pressureretaining cylinder is $\Delta P_{b}=15.69 \mathrm{MPa}$. Because the pressure loss is so large, it was necessary to design a pressure-compensation device precharged with nitrogen to offset the pressure loss caused by the expansion of the pressure-retaining cylinder. To determine how much compensation pressure is required, the pressure loss of the cylinder of the pressure-compensation device needs to also be calculated.

Therefore, according to Eqs. (1)-(12), the wall thickness of the cylinder of the pressure-compensation device is $\delta_{c}=$ $16 \mathrm{~mm}$, and the pressure drop of the cylinder of the pressurecompensation device is calculated as $\Delta P_{c}=14.46 \mathrm{MPa}$. Therefore, the total pressure loss in the sampler caused by pressure change and temperature difference is $\Delta P_{s}=\Delta P_{b}+$ $\Delta P_{c}=30.15 \mathrm{MPa}$. Therefore, when precharging the pressurecompensation device, nitrogen should be precharged to a pressure not less than $30 \mathrm{MPa}$ to make up for losses due to deformation caused by temperature and pressure changes.

\section{b. Large-diameter seal}

Considering the fact that the sampler would be influenced by the extremely high-pressure environment in the deep water, a conical surface with an O-ring sealing structure and combined sealing ring structure were utilized to ensure sealing and pressure-retaining under ultrahigh pressures. The structure of the movable seal piece and pressure-retaining cylinder sued for the O-ring combined with retainer ring is shown in Fig. 2. The sampling device and pressure-retaining cylinder using conical structure surface with a perfluororubber O-ring is shown in Fig. 3. Of the two sealing methods, the metal-to-metal contact seal is the main seal, and the O-ring or O-ring with retainer ring represent secondary seals. The specific pressure achieved by the conical surface seal is related to cone angle, contact surface width and axial force, but the cone angle has an especially large influence on the specific pressure of sealing, making its design especially influential and important.

Under the action of axial force $F_{1}$, the gas-tight piece exerts the specific pressure $M$ on the movable seal piece. At this time, the forces acting on the gas-tight piece include axial force $F_{1}$, conical surface sealing reaction force $F_{N}$, and sealing surface friction force $F_{2}$, which can be obtained from force analyses as follows:

$$
F_{1}=2 F_{N} \sin \phi+2 F_{2} \cos \phi
$$

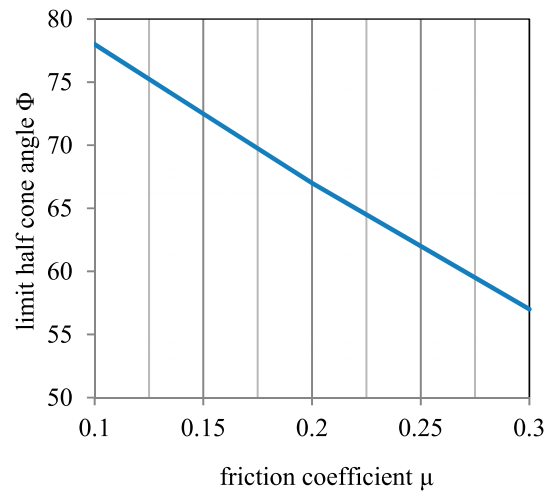

FIG. 5. Relationship between limit half-cone angle and friction coefficient. 


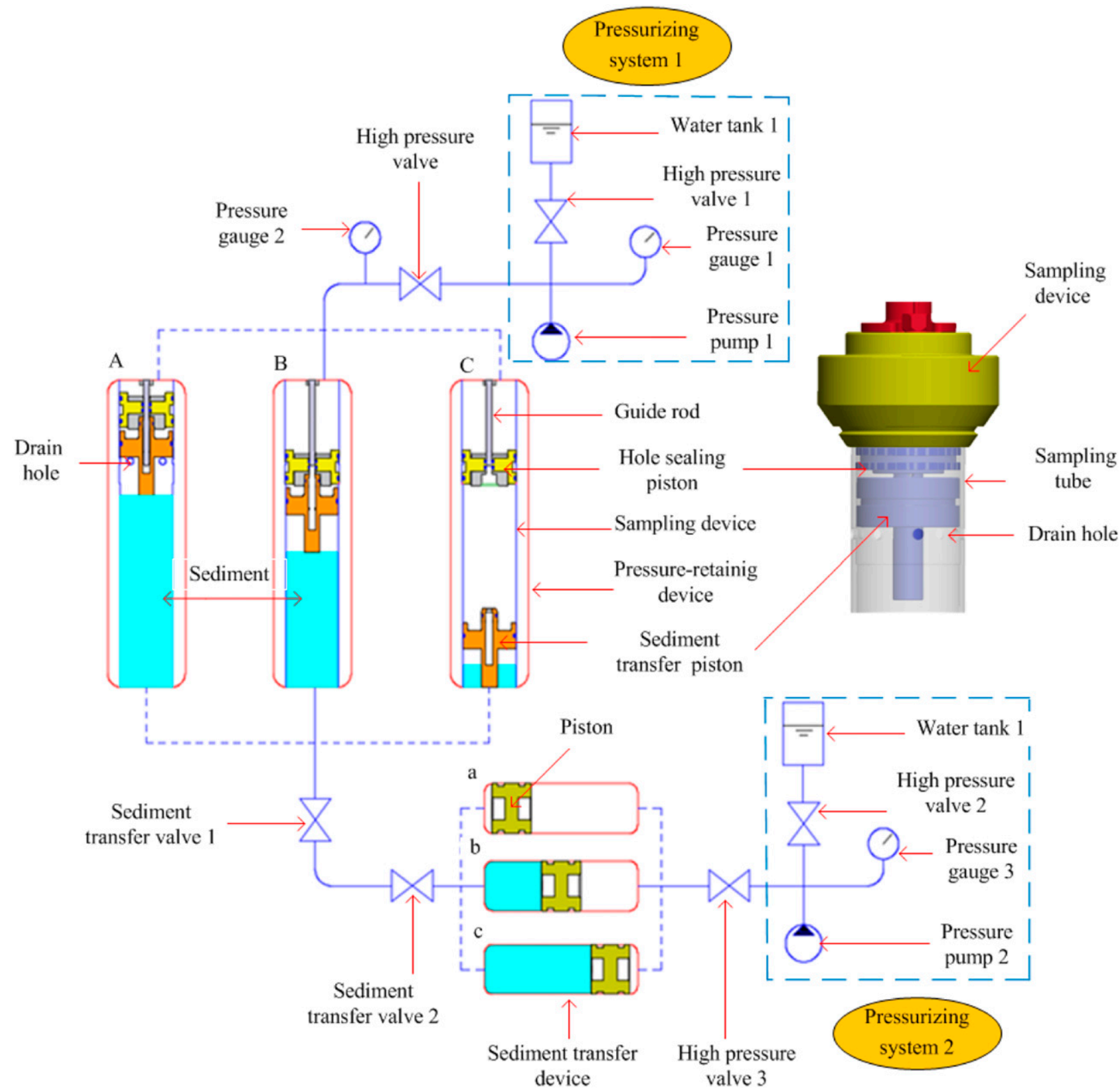

FIG. 6. Schematic diagram of the sample transfer system.

where $\phi$ is the half-cone angle,

$$
\begin{aligned}
F_{2} & =u F_{N}, \quad \text { and } \\
2 F_{N} & =\pi D_{a} b M .
\end{aligned}
$$

Here, $\mu$ is the friction coefficient, $b$ is the sealing cone surface width, $D_{a}$ is the sealing cone average surface diameter, and $M$ is the specific sealing pressure. These can be obtained from Eqs. (13)-(15). Let

$$
\begin{aligned}
& n=1+\mu / \tan \phi \quad \text { and } \\
& a=1 /[\sin \phi(1+\mu / \tan \phi)] ;
\end{aligned}
$$

then there is

$$
M=\frac{F_{1}}{\pi D_{a} b} a .
$$

It can be seen from Eq. (17) that the factors affecting the specific pressure of the seal include axial force $F_{1}$, average diameter of the seal cone surface $D_{a}$, sealing surface width $b$, and coefficient $a$, which are functions of friction coefficient $\mu$ and half-cone angle $\phi$. When $a>1$, the conical surface seal is superior to a flat seal. Therefore, for a constant friction coefficient $\mu$ whose value range typically ranges from 0.1 to 0.3 , the cone angle that can obtain the maximum specific sealing pressure by using the same axial force is optimal, and the coefficient $a$ is a maximized under the optimum cone angle, and the half-cone angle ranges from $0^{\circ}$ to $90^{\circ}$. The optimal angle needs to be calculated using a program to optimize. 


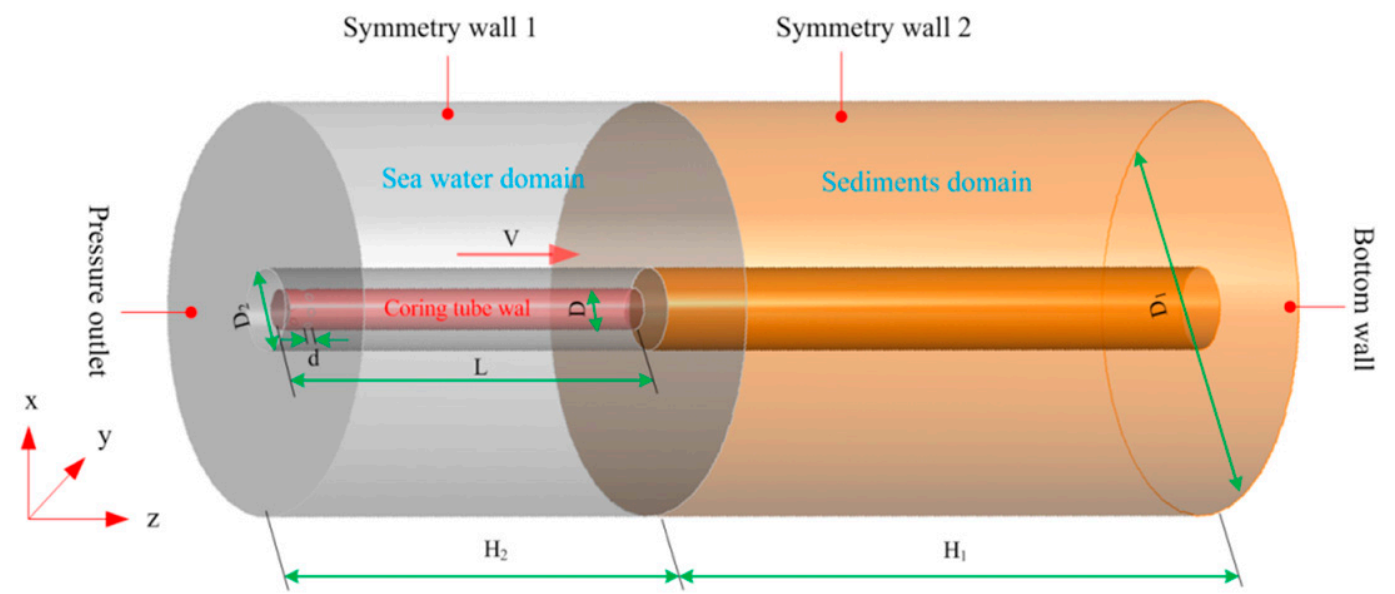

FIG. 7. Three-dimensional computational fluid dynamics model of sampling.

It can be seen from Fig. 4 that the values decreases monotonically with increases in the half-cone angle $\phi$. This meant that there is no inflection point in the curve, that is, there is no optimal half-cone angle $\phi^{\prime}$, but there is a limit half-cone angle $\Phi$ that makes $a<1$ when $\phi>\Phi$. It can be seen from Fig. 5 that the limit half-cone angle $\Phi$ decreases with increases in the friction coefficient $\mu$ and shows a linear change.

Therefore, at a constant conical surface width, constant average sealing diameter, constant axial force, reducing the halfcone angle can increase the specific sealing pressure and improve the sealing performance. Because the gas-tight pieces and movable seal pieces are both made of TC4 titanium alloy, the dynamic friction coefficient is $0.1-0.3$ when the environment temperature was between $0^{\circ}$ and $30^{\circ} \mathrm{C}$, and the corresponding maximum limit half-cone angle is $57^{\circ}$. This meant the half-cone angle should be set to less than $57^{\circ}$. Because of manufacturing and processing consideration, the half-cone angle was set to be $35^{\circ}$ in this design. At the same time, to ensure the effectiveness of the conical surface seal, matching grinding was adopted to reduce the friction coefficient.

\section{c. Sediment transfer system}

When the sampler is transferred to the sea surface after sampling, a pressure-retaining transfer system for the sediment is necessary for experimental analysis. Figure 6 shows a schematic diagram of the pressure-retaining transfer system; A, B, and $\mathrm{C}$ show the motions of the piston in the sampling tube during the sediment transfer, and a, b, and c show the motion of the piston in the sample transfer device. After sampling, the sediment is kept in the pressure-retaining cylinder (shown in A-a). Before transfer, pressurizing system 1 is connected to the sample high-pressure valve, and pressurizing system 2 is connected to the sample transfer device. Then pressurizing system 1 slowly pressurizes the pressure-retaining cylinder until the readings of pressure gauge 1 and pressure gauge 2 are equal. Next, pressurizing system 2 is activated and the high-pressure valve 3 is opened to slowly pressurize the sample transfer device until the readings of pressure gauge 3 and pressure gauge 2 are equal.
Sediment transfer valve 1 and sediment transfer valve 2 are then opened, and by operating pressurizing system 1 and pressurizing system 2 synchronously, the pressure difference between system 1 and system 2 can be maintained at about $2 \mathrm{MPa}$ (the pressure of system 1 is greater than that of system 2). At this time, the hole-sealing piston and the sample squeezing piston in the sampling tube will move down under

Phase 1.Volume Fraction
Contour 1
\begin{tabular}{|l}
$1.000 \mathrm{e}+00$ \\
$9.000 \mathrm{e}-01$ \\
$8.000 \mathrm{e}-01$ \\
$7.000 \mathrm{e}-01$ \\
$6.000 \mathrm{e}-01$ \\
$5.000 \mathrm{e}-01$ \\
$4.000 \mathrm{e}-01$ \\
$3.000 \mathrm{e}-01$ \\
$2.000 \mathrm{e}-01$ \\
$1.000 \mathrm{e}-01$ \\
$0.000 \mathrm{e}+00$
\end{tabular}

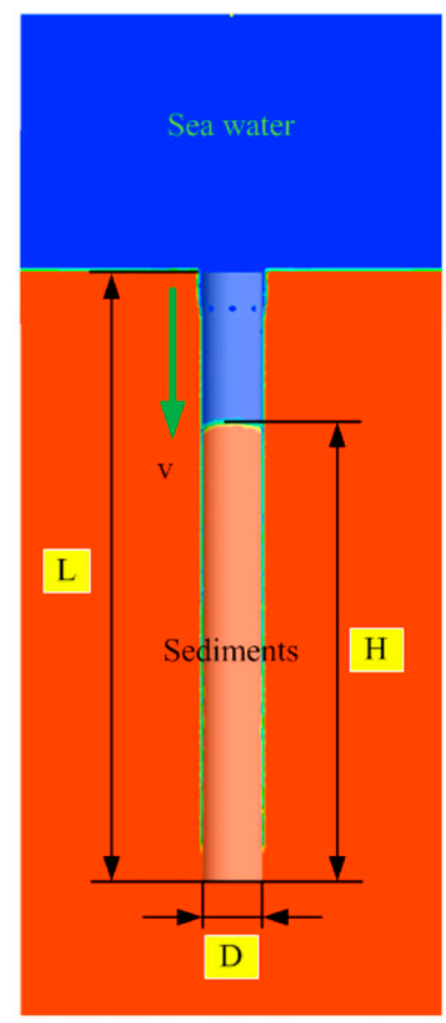

FIG. 8. Sketch map of sampling. In the color key, "e" indicates that the preceding value should be multiplied by 10 raised to the following sign and power. 
the pressure. When the hole-sealing piston reaches the position of the sampling tube drainage hole, the pressure in the upper and lower cavities of the hole-sealing piston in the sampling tube will equilibrate, and the hole-sealing piston will stop moving (shown in B-b). As the pressure continues to increase, under the force of the pressure difference, the squeeze piston of the sampling tube will continue to push the sediment downward. When the pressure of system 1 is greater than the pressure of system 2 by a sufficient amount, the pressure of system 2 is released, while the pressure value of pressure gauge 1 does not change, and the sediment is transferred to the transfer container (shown in C-c). Sediment transfer valve 2 and the high-pressure valve 3 are close, and then the sediment transfer device is transferred to the laboratory for analysis of the sediment sample.

\section{Simulation of sampling}

This section simulated the soft viscous seabed sediments as non-Newtonian Herschel-Bulkley viscoplastic fluids and established a numerical model for the sampling based on the volume-of-fluid method. The influence rules of the sampling tube diameter, penetration velocity, and sediments dynamic viscosity on coring rate were studied.

\section{a. Computational fluid dynamics model}

Assuming that the penetration depth of the sampling tube into the sediments is $L$, the height of the sediments entering the sampling tube is $H$, and the coring volume is $Q$, then the coring rate is $\lambda$ :

$$
\lambda=\frac{H}{L} \times 100 \% .
$$

The coring rate $\lambda$ is an important index of deep-sea sediments sampling equipment. The larger that $\lambda$ is, the better the sampling performance is; the lower that $\lambda$ is, the worse the sampling performance is.

Before the establishment of a computational fluid dynamics model, the sampling device is simplified to a round tube with a closed upper end and an open lower end. The velocity during penetration of the sampling tube can be set by writing userdefined-function programs. The entire computational domain was divided into seawater area and sediments area. The settings and parameters of the computational domain are shown in Fig. 7.

\section{b. Computational parameters and boundary conditions}

The multiphase model and the realizable $k-\varepsilon$ turbulence model were used to simulate the flow field in the computational domain. The $3 \mathrm{D}$ single precision was used in this calculation, and the dynamic grid change was controlled by a dynamic layering method. For outlet boundary conditions, the boundary conditions of pressure outlet were adopted, with a gauge pressure of zero. For wall boundary conditions, the lower boundary of the computational domain adopted rigid boundary, and for the cylindrical surface of the computational domain a symmetric boundary was adopted.

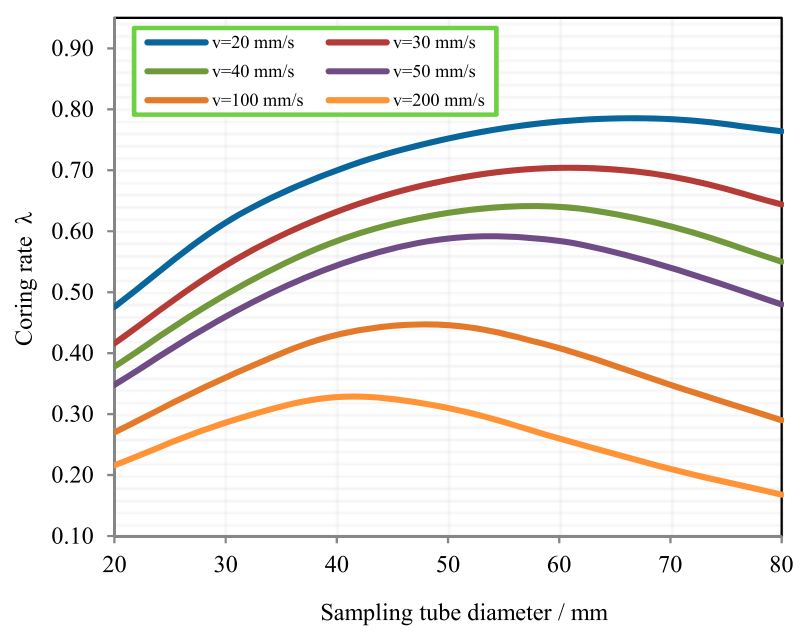

FIG. 9. The influence curve of the sampling tube diameter on the coring rate.

\section{c. Simulation results}

The sampling tube length, diameter, and penetration velocity will affect the sediments entering the tube, which needs to overcome its own viscous resistance, interfacial surface tension, and water resistance during sampler penetration. When sampling was finished, the height of sediments that has entered the tube can be clearly observed, and the height of the sediments in the sampling tube was always less than the sampling tube's penetration depth, as shown in Fig. 8.

\section{1) INFLUENCE OF THE SAMPLING TUBE DIAMETER}

The sampler diameter ranged from 20 to $80 \mathrm{~mm}$, and six different velocities of penetration were used. Figure 9 shows the coring rate first increased and then decreased with increases in the sampling tube diameter. When the penetration velocity was $200 \mathrm{~mm} \mathrm{~s}^{-1}$ and the sampling tube diameter was $40 \mathrm{~mm}$, the coring rate was about 0.33 . When the penetration velocity was $20 \mathrm{~mm} \mathrm{~s}^{-1}$ and the sampling tube diameter

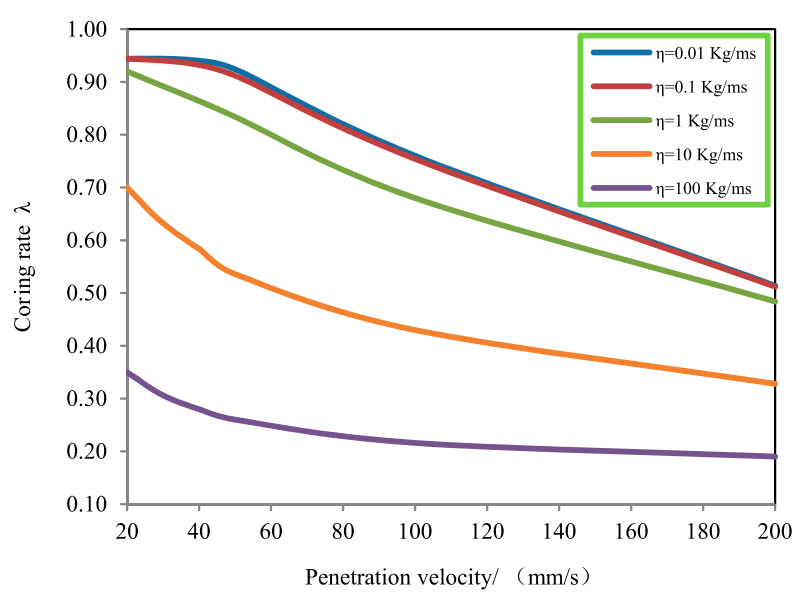

FIG. 10. The influence curve of the penetration velocity on the coring rate. 
was $70 \mathrm{~mm}$, the coring rate was around 0.8 . Therefore, under the condition of a known penetration velocity, a reasonable sampling tube diameter is an important guarantee for obtaining samples with a high coring rate.

\section{2) INFLUENCE OF THE PENETRATION VELOCITY}

Numerical simulations were carried out for the penetration velocities of $20,30,40,50,100$, and $200 \mathrm{~mm} \mathrm{~s}^{-1}$. For these calculations, the sampling tube length was $500 \mathrm{~mm}$ and the sampling tube diameter was $40 \mathrm{~mm}$. When the sediments dynamic viscosity was 0.1 or $0.01 \mathrm{~kg} \mathrm{~m} \mathrm{~s}^{-1}$, the coring rate first remained unchanged and then gradually decreased with the increasing of penetration velocity. This inflection point is related to the sediments dynamic viscosity, as shown in Fig. 10.

\section{3) INFLUENCE OF SEDIMENTS DYNAMIC VISCOSITY}

Figure 11 shows the influence rules of the different sediments dynamic viscosities on the coring rate. For these simulations, the sampling tube length was $500 \mathrm{~mm}$, and the sampling tube diameter was $40 \mathrm{~mm}$. When the viscosity was less than 0.1 , the decreasing trend observed in coring rate as viscosity increased was not obvious. When the viscosity was 1,10 , or $100 \mathrm{~kg} \mathrm{~m} \mathrm{~s}^{-1}$, the decreasing trends in coring rate as viscosity increased was obvious. Before sampling, it was necessary to measure or estimate the characteristic parameters of sediments, such as dynamic viscosity, so as to facilitate the optimal design of structural parameters of the sampler using realistic values.

According to the simulation calculation model and results in this section, it can provide a theoretical basis for the design of the sampling tube diameter and sampling velocity parameters.

\section{Experimental study}

At present, the novel sampler has been successfully manufactured. The laboratory high-pressure chamber and internal pressure experiments have been carried out to test the pressurebearing and pressure-retaining performance of the sampler under a simulated 11000-m-depth high-pressure sea-bed environment. On this basis, a lake test was carried out to test the suitability between the sampler and HOV's mechanical arm.

\section{a. High-pressure chamber experiment}

Simulating the characteristics of an ultrahigh pressure in deep-sea environment, high-pressure chamber and internal pressure experiments were carried out; the high-pressure chamber experiment was carried out first. The pressure in the high-pressure chamber was $127 \mathrm{MPa}$ (1.10 times the working pressure), and the required pressure values of the pressurization process were as follows: $P \geq 115 \mathrm{MPa}, 1.1 P \leq P_{t} \leq 1.25 P$, $T_{1} \leq 3 \mathrm{~h}, T_{2} \geq 3 \mathrm{~h}$, and $T_{4} \leq 3 \mathrm{~h}$. Figure 12 shows the pressure assessment requirements of the pressure bearing structure according to the project.

The experiment was divided into two steps. In the first step, the key components and high-pressure valves were tested; no abnormal noise was observed during the experiment and no deformation afterward. In the second step, the pressure-retaining sampler was sealed as a whole and put into the high-pressure chamber, which was slowly

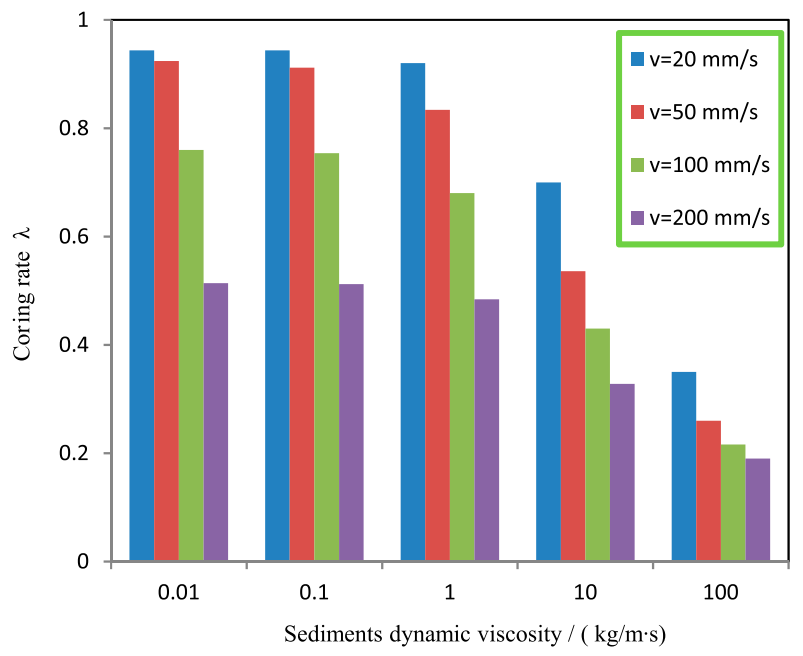

FIG. 11. The influence curve of the sediments dynamic viscosity on the coring rate.

pressurized to the experimental pressure of $127 \mathrm{MPa}$ where it remained for $30 \mathrm{~min}$. The actual experimental pressure graph was shown in Fig. 13, in the initial pressurization process, due to the limitation of the flow of the high-pressure chamber, the actual pressurization to $115 \mathrm{MPa}$ took $4.75 \mathrm{~h}$. After the experiment, both the pressure-retaining cylinder and the conical surface sealing high-pressure valves exhibited no cracks or obvious deformations. There was no color change in the moisture test paper in the sealed environment, which meant no leakage. The experimental results showed that the designed pressure-retaining cylinder had good pressure-bearing and sealing performance and can realize safe sealing at a depth of $11000 \mathrm{~m}$.

\section{b. Internal pressure experiment}

The pressure-bearing performance of the sampler was verified using an internal pressure experiment. According to the

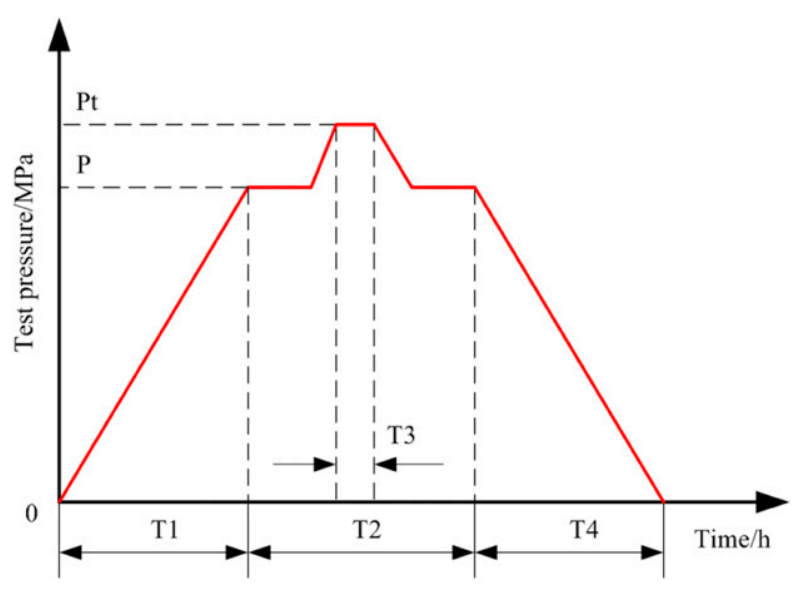

FIG. 12. Pressurization curve, where, $\mathrm{Pt}$ is maximum test pressure $(\mathrm{Pt}=1.15 P), P$ is working pressure, $\mathrm{T} 1$ is pressurization time, $\mathrm{T} 2$ is holding time at working pressure, $\mathrm{T} 3$ is holding time at maximum test pressure, and $\mathrm{T} 4$ is relief time. 


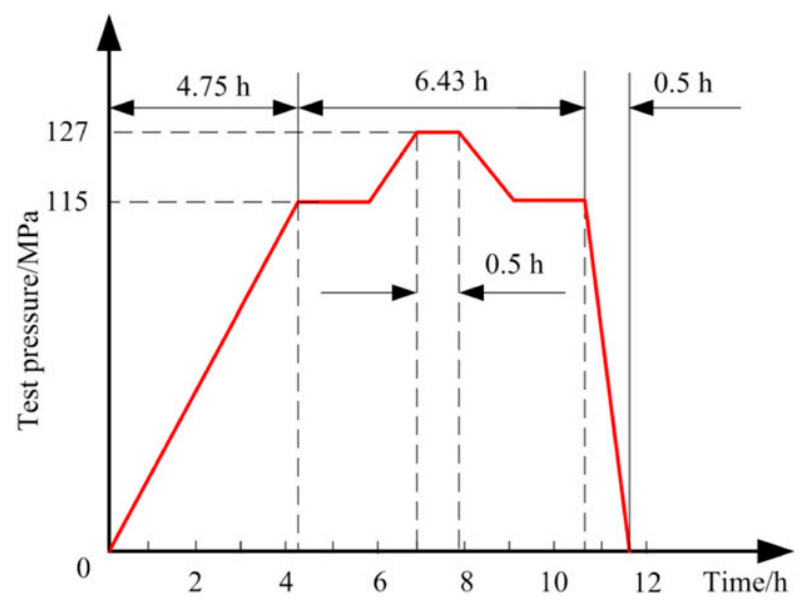

FIG. 13. Actual experimental pressurization curve.

design and calculation of engineering pressure vessel (Wang and Mark 2020) and the internal pressure test assessment standard of this project, the internal pressure for this experiment was $173 \mathrm{MPa}$ (1.5 times the working pressure). As shown in Fig. 14, the pressurizing system was connected to the pressure-retaining cylinder, and the sample high-pressure valve was opened, slowly pressurizing the pressure-retaining cylinder to $17 \mathrm{MPa}$ ( $10 \%$ of the experimental pressure) through the sample high-pressure valve, that pressure was and held for $5 \mathrm{~min}$; pressure was then increased to $86 \mathrm{MPa}(50 \%$ of the experimental pressure), where it was maintained for $5 \mathrm{~min}$; then the pressure was increased to $103 \mathrm{MPa}$ for $5 \mathrm{~min}$; then to $115 \mathrm{MPa}$ for $180 \mathrm{~min}$; then sequentially increased to the experimental pressures of 132, 149, 166, and $173 \mathrm{MPa}$ (slowly pressurizing from the working pressure to the experimental by $10 \%$ maximum pressure increments), maintaining each pressure for $5 \mathrm{~min}$, except for the experimental pressure of $173 \mathrm{MPa}$, which was maintaining for $30 \mathrm{~min}$. The system was checked for any leakage at each connection and along connecting pipes, the pressure gauge was observed for any change in value, and experimental data were recorded; next, the pressure-relief valve was opened, and the working pressure was slowly relieved to $115 \mathrm{MPa}$, where it was maintained for $180 \mathrm{~min}$ while monitoring for changes in the pressure value and recording experimental data. The pressure was then released step by step in the reverse of the incremental changes during pressurization, the pressure at each step was held for 5 min while monitoring for changes in the pressure value and recording experimental data, actual experimental pressure should be greater than the standard pressure, the standard pressure and actual experimental pressure are shown in Table 3.

At the maximum actual experimental pressure of $174 \mathrm{MPa}$, which was 1.5 times the working pressure, the pressure-bearing cylinder and large-diameter sealing structure of the novel sampler exhibited no damage or leakage. At the working pressure (actual experimental pressure was greater than $115 \mathrm{MPa}$ ), the pressure drop in the pressure-retaining cylinder was about $3.5 \%-4.0 \%$, with an average pressure drop of $3.6 \%$, and the average pressure-retaining rate within $180 \mathrm{~min}$ was as high as $96.4 \%$, which met the performance index requirements that stipulate a pressure-retaining rate of more than or equal to $80 \%$. The experimental results showed that the sampler had good pressure-bearing and pressure-retaining performance and can be used for safe and reliable sealing and pressureretaining in deep-sea environments at $11000 \mathrm{~m}$.

\section{c. Lake test}

A lake test with a depth of about $30 \mathrm{~m}$ was carried out to test the suitability between the sampler and HOV's

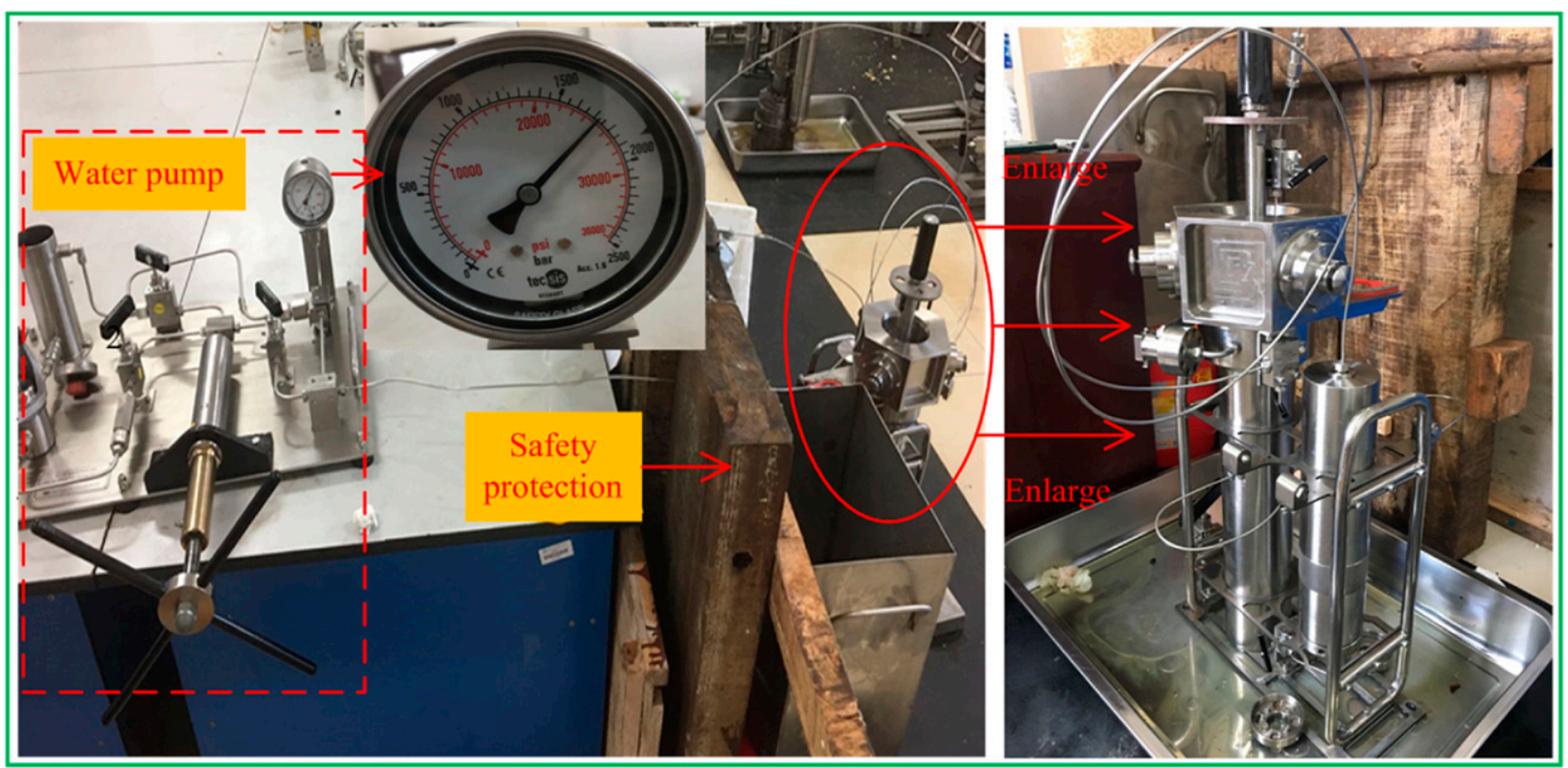

FIG. 14. Photographic diagram of the experimental internal pressure system. 
TABLE 3. Data from the internal pressure experiment.

\begin{tabular}{rccccc}
\hline \hline & $\begin{array}{c}\text { Standard } \\
\text { pressure } \\
\text { No. }\end{array}$ & $\begin{array}{c}\text { Actual } \\
\text { pressure } \\
(\mathrm{MPa})\end{array}$ & $\begin{array}{c}\text { Pressure- } \\
\text { retaining } \\
\text { time (min) }\end{array}$ & $\begin{array}{c}\text { Pressure } \\
\text { loss } \\
(\mathrm{MPa})\end{array}$ & $\begin{array}{c}\text { Pressure } \\
\text { loss } \\
\text { rate (MPa) }\end{array}$ \\
\hline 1 & 17 & 30 & 5 & 0.5 & $1.7 \%$ \\
2 & 86 & 90 & 5 & 1.5 & $1.7 \%$ \\
3 & 103 & 105 & 5 & 2.0 & $1.9 \%$ \\
4 & 115 & 115 & 180 & 4.5 & $3.9 \%$ \\
5 & 132 & 135 & 5 & 2.0 & $1.5 \%$ \\
6 & 149 & 150 & 5 & 2.5 & $1.7 \%$ \\
7 & 166 & 166 & 5 & 3.5 & $2.1 \%$ \\
8 & 173 & 174 & 5 & 2.5 & $1.4 \%$ \\
9 & 166 & 169 & 5 & 1.0 & $0.6 \%$ \\
10 & 149 & 157 & 5 & 1.5 & $1.0 \%$ \\
11 & 132 & 142 & 5 & 1.0 & $0.7 \%$ \\
12 & 115 & 123 & 180 & 4.0 & $3.3 \%$ \\
13 & 103 & 110 & 5 & 0.5 & $0.5 \%$ \\
14 & 86 & 96 & 5 & 0.5 & $0.5 \%$ \\
15 & 17 & 25 & 5 & 0.5 & $2.9 \%$ \\
\hline
\end{tabular}

mechanical arm. This test was completed at the lake test site of 702 Institute of China Ship Scientific Research Center between 20 and 23 May 2020. The specific test steps are as follow:

1) The sampler was fixed in the tool basket of the HOV, the presampling test was carried out to ensure that there was no interference between the manipulator, the sampler, and the HOV in the sampling process, and then it descended to the lakebed with the HOV, as shown in Fig. 15.
2) The HOV's mechanical arm was controlled to grab the handle of the sampler and remove it from the bracket and then to make the sampling device vertical downward.

3) The sampling device was inserted into the sediments vertical downward about $350 \mathrm{~mm}$ and then pulled out, as shown in Fig. 15a.

4) The sampling device was moved to the mud scraping ring and pulled vertically upward to remove the adhesion sediment on the surface of the sampling tube, as shown in Fig. 15b.

5) The sampling device was moved directly above the sampler and fixed to the pressure retaining cylinder until it was locked and sealed, as shown in Figs. 15c and 15d.

6) A check was done to ensure that the locking device was in the correct place. If not, it was necessary to press the handle again until its action was in the correct place.

All the sampling operations of the sampler were completed, which indicated that the suitability between the sampler and HOV's mechanical arm was good. However, most of the samples taken were water samples, with very little sediment. No complete columnar sediment samples were obtained from the lakebed because of its hard surface. Sea trials are expected to be carried out in the Mariana Trench with a depth of about $11000 \mathrm{~m}$ in the next few months to further test the sampler's sampling and pressure-retaining performance.

\section{Conclusions}

A novel sampler was first proposed to obtain intact sediment samples at full ocean depth $(11000 \mathrm{~m})$. The pressure-bearing
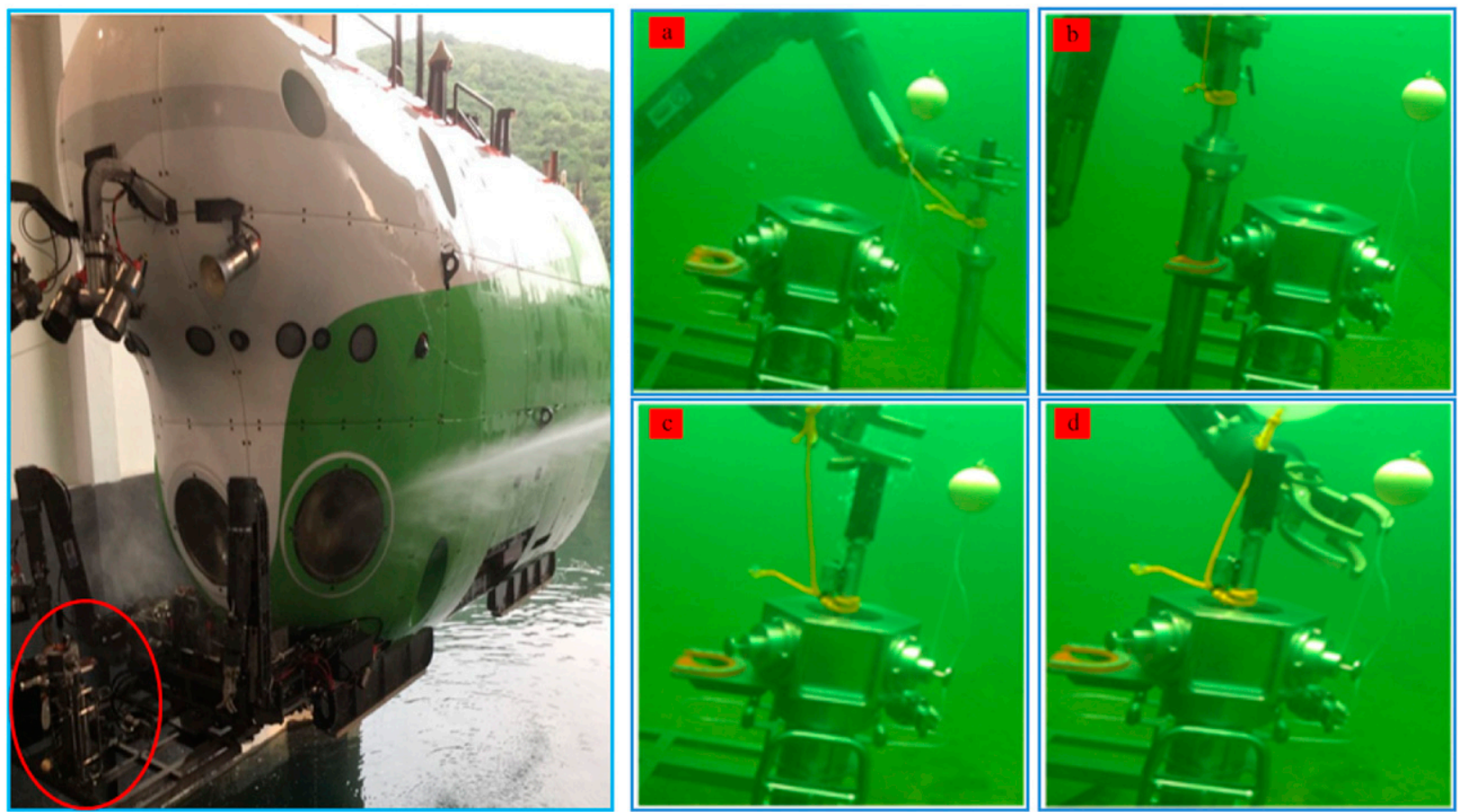

FIG. 15. Underwater sampling test. 
test of the sampler showed that the sampler had a good pressure-bearing and pressure-retaining performance, and a successful lake test indicated that the suitability between the sampler and HOV's mechanical arm was good. It can be deployed by ROV or HOV to collect intact original samples for scientific research in fields such as seabed geological resource exploration, chemistry, and life processes of microbial communities.

According to the requirements of the deep-sea sampling equipment project that belongs to the National Key R\&D Program of China, this novel sampler was designed to provide pressure-retaining sediment samples to relevant research institutes for scientific research, which was a basis for the followup work. On this basis, more functions of the sampler will be added, such as an active temperature-retaining structure that can control the temperature of the sampler, a multifunctional instrument to conduct in situ tests on the end resistance and temperature of the stratum, and the CT scanning technology used for chemical and physical analysis of the sample. It is believed that the multifunctional sampler will be widely applicable in deep-sea fields of life processes and environmental research.

Acknowledgments. This work was supported by the National Key Research and Development Program of China (Grant 2016YFC0300502) and the National Natural Science Foundation of China (Grants 51705145 and 517779092). It was also supported by the Hunan Province Natural Science Foundation (Grant 2019JJ50182).

\section{REFERENCES}

Abegg, F., H.-J. Hohnberg, T. Pape, G. Bohrmann, and J. Freitag, 2008: Development and application of pressure-core-sampling systems for the investigation of gas-hydrate-bearing sediments. Deep-Sea Res. I, 55, 1590-1599, https://doi.org/10.1016/ j.dsr.2008.06.006.

Case, D. H., A. Ijiri, Y. Morono, P. Tavormina, V. J. Orphan, and F. Inagaki, 2018: Aerobic and anaerobic methanotrophic communities associated with methane hydrates exposed on the seafloor: A high-pressure sampling and stable isotopeincubation experiment. Front. Microbiol., 8, 25-69, https:// doi.org/10.3389/fmicb.2017.02569.

Cheng, D. X., 2007: Mechanical Engineers' Handbook. Vol. 1, 5th ed., Chemical Industry Press, 1674 pp.

Drazen, J. C., and J. Yeh, 2012: Respiration of four species of deep-sea demersal fishes measured in situ in the eastern North Pacific. Deep-Sea Res. I, 60, 1-6, https://doi.org/10.1016/j.dsr.2011.09.007.

He, S. D., Y. D. Peng, Y. P. Jin, B. Y. Wan, and G. P. Liu, 2020: Review and analysis of key techniques in marine sediment sampling. Chinese J. Mech. Eng., 33, 66, https://doi.org/10.1186/s10033-020-00480-0.

Huang, H. C., L. Huang, and W. Ye, 2018: Optimizing preloading pressure of pre-charged gas for isobaric gas-tight hydrothermal samplers. J. Pressure Vessel Technol., 140, 021201, https:// doi.org/10.1115/1.4038901.

Huang, Z. H., S. J. Liu, and B. Jin, 2006: Accumulator-based deepsea microbe gastight sampling technique. China Ocean Eng., 20, 335-342.
Kubo, Y., Y. Mizuguchi, F. Inagaki, and K. Yamamoto, 2014: A new hybrid pressure-coring system for the drilling vessel Chikyu. Sci. Drill., 17, 37-43, https://doi.org/10.5194/sd-17-37-2014.

Li, Z. A., F. D. Zhang, and Y. D. Wei, 2019: Design of Penstock. China Petrochemical Press, 384 pp.

Lu, D. Q., Z. Ding, D. Li, and B. Liu, 2019: Studies and applications of cobalt-rich crust core samplers mounted on "Jiao Long" manned submersibles. China Mech. Eng., 30, 603-607, https:// doi.org/10.3969/j.issn.1004-132X.2019.05.014.

Masayuki, K., U. Satoru, and Y. Masato, 2006: Pressure temperature core sampler (PTCS). J. Japanese Assoc. Petroleum Technol., 71, 139-147, https://doi.org/10.3720/ japt.71.139.

Mittelstaedt, E., J. Escartín, N. Gracias, J.-A. Olive, T. Barreyre, A. Davaille, M. Cannat, and R. Garcia, 2012: Quantifying diffuse and discrete venting at the Tour Eiffel vent site, Lucky Strike hydrothermal field. Geochem. Geophys. Geosyst., 13, Q04008, https://doi.org/10.1029/2011GC003991.

Nunoura, T., and Coauthors, 2015: Hadal biosphere: Insight into the microbial ecosystem in the deepest ocean on Earth. Proc. Natl. Acad. Sci. USA, 112, E1230-E1236, https://doi.org/ 10.1073/pnas.1421816112.

Peoples, L. M., M. Norenberg, D. Price, M. McGoldrick, M. Novotny, A. Bochdansky, and D. H. Bartlett, 2019: A full-ocean-depth rated modular lander and pressure-retaining sampler capable of collecting hadal-endemic microbes under in situ conditions. Deep-Sea Res. I, 143, 50-57, https://doi.org/10.1016/ j.dsr.2018.11.010.

Peterson, M. N. A., 1984: Design and operation of a wire-line pressure core barrel. Deep Sea Drilling Project Tech. Rep. PB-85-112282/XAB TR-16, 214 pp., https://www.osti.gov/ biblio/6396456.

Pettigrew, T. L., 1992: Design and operation of a wire-line pressure core sampler (PCS). ODP Tech. Note 17, 269 pp., http://wwwodp.tamu.edu/publications/tnotes/digital/tnote_17.pdf.

Ramirez-Llodra, E., A. Brandt, R. Danovaro, E. Escobar, and C. R. German, 2010: Deep, diverse and definitely different: unique attributes of the world's largest ecosystem. Biogeosciences, $\mathbf{7}$, 2851-2899, https://doi.org/10.5194/bg-7-2851-2010.

Ritchie, H., A. J. Jamieson, and S. B. Piertney, 2017: Population genetic structure of two congeneric deep-sea amphipod species from geographically isolated hadal trenches in the Pacific Ocean. Deep-Sea Res. I, 119, 50-57, https://doi.org/10.1016/ j.dsr.2016.11.006.

Schultheiss, P. J., M. E. Holland, and G. D. Humphrey, 2009: Wireline coring and analysis under pressure: recent use and future developments of the HYACINTH system. Sci. Drill., 7, 44-50, https://doi.org/10.2204/iodp.sd.7.07.2009.

Shillito, B., J. Ravaux, J. Sarrazin, M. Zbinden, P. Sarradin, and D. Barthelemy, 2015: Long-term maintenance and public exhibition of deep-sea hydrothermal fauna: The Abyss Box project. Deep-Sea Res. II, 121, 137-145, https://doi.org/10.1016/ j.dsr2.2015.05.002.

Wang, S., S. J. Wu, and C. J. Yang, 2020: The pressure compensation technology of deep-sea sampling based on the real gas state equation. Acta Oceanol. Sin., 39, 88-95, https://doi.org/ 10.1007/s13131-020-1637-6.

Wang, X. M., and W. Z. Mark, 2020: Design and Calculation of Engineering Pressure Vessel. National Defense Industry Press, 478 pp. 